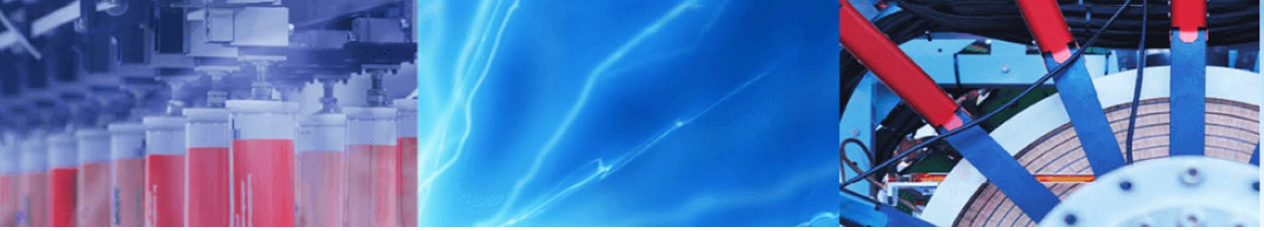

Research Article

\title{
Extraction of alumina from high-alumina coal ash using an alkaline hydrothermal method
}

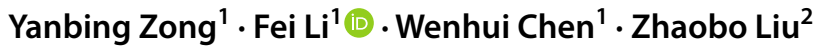

(c) Springer Nature Switzerland AG 2019

\begin{abstract}
As a type of industrial solid waste with huge emission and heap stock, high-aluminum pulverized coal ash has a significant negative impact on resources and the environment. At the same time, as a secondary resource, its aluminum content can reach $50 \%$, which is close to that of medium-grade bauxite; thus, it can be used as a substitute for bauxite resources. We propose a new method for extracting aluminum from fly ash via leaching. By designing the thermal reaction system of the molten brine, high-purity hydroxyl sodalite (90.2\%) was prepared from fly ash. In this study, aluminum and other valuable elements were extracted using a hydrochloric acid leaching method from prepared high-purity hydroxyl sodalite in the form of ions by converting fly ash into a fixed hydroxyl sodalite solid product system. The major factors affecting the leaching rate are the hydrochloric acid concentration, liquid-solid product quality ratio, reaction temperature, and reaction time. Through analysis and calculation, within the scope of study, the leaching rate of aluminum reached more than $90 \%$. The optimal experimental conditions are a leaching concentration of $1.5 \mathrm{~mol} / \mathrm{L}$, a liquid-solid volume-mass ratio of 20, a leaching time of $120 \mathrm{~min}$, and a leaching temperature of $85^{\circ} \mathrm{C}$. Aluminum exists in the leaching solution in the form of $\mathrm{Al}^{3+}$, while the silica is partly dissolved in the hydrochloric acid solution; the other part remains in the solid phase as the main part of the hydrochloric acid leaching residue in the form of silica gel. In addition, this method not only can treat high-alumina fly ash, but also can be applied to other types of fly ash.
\end{abstract}

Keywords Bauxite $\cdot$ High-alumina fly ash $\cdot$ Hydroxy sodalite $\cdot$ Hydrothermal aluminum process

\section{Introduction}

According to statistics, the proven bauxite reserves in China at the end of 2017 were approximately 830 million tons, accounting for $2.96 \%$ of the world's reserves; however, China produces approximately $25 \%$ of the world's bauxite. The static mining life of bauxite in China is only 14 years, which is far behind the global average of 102 years if the current situation does not change. In addition, some bauxite resources that have been proven in China are also difficult to exploit and not easy to utilize [1]. Up to now, China has imported more than 50 million tons of bauxite per year. At the same time, in prospecting, according to the current forecast, more than 20 billion tons of bauxite resources may be found in the future in China to alleviate the urgent situation of scarce bauxite resources. Therefore, in general, the exploitation and utilization of bauxite resources in China is not optimistic; thus, it is particularly important to seek new resources and sustainable utilization $[2,3]$.

Fly ash forms when pulverized coal is burned at a high temperature. It is a type of white or gray powder similar to volcanic ash formed under the condition of rapid cooling. It is a type of industrial solid waste with a large amount of

Fei Li, 15532152581@163.com; Yanbing Zong, zongyb@ustb.edu.cn; Wenhui Chen, 18101123505@163.com; Zhaobo Liu, liuzhaobo@enfi.com.cn | ${ }^{1}$ School of Metallurgical and Ecological Engineering, University of Science and Technology, Beijing, Beijing 100083, China. ${ }^{2}$ China Nonferrous Engineering and Research Institute (China ENFI Engineering Corporation), No. 12 Fuxing Road, Beijing 100038, China. 
production [4]. A total of $76 \%$ of China's electricity is generated by coal. It is estimated that the cumulative stockpile of fly ash generated by coal combustion will exceed 600 million tons $[5,6]$ by 2020 . Fly ash storage not only occupies a large amount of land, but also causes serious environmental pollution. During recent years, high-alumina fly ash is produced by fine grinding some aluminum-rich coals in central and western Inner Mongolia and northern Shanxi. Among these [7], $\mathrm{Al}_{2} \mathrm{O}_{3}+\mathrm{SiO}_{2}+\mathrm{Fe}_{2} \mathrm{O}_{3} \geq 80 \%$. The main characteristic is that the content of $\mathrm{Al}_{2} \mathrm{O}_{3}$ is high, generally more than $38 \%$; the highest is greater than $50 \%$. It is equivalent to the content of $\mathrm{Al}_{2} \mathrm{O}_{3}$ in trihydrate bauxite abroad. China's high-alumina fly ash stone contains a large number of minerals such as kaolin, orthoclase, and bauxite. It is a valuable aluminum resource with high economic development value [8].

Developing the comprehensive utilization of coal-based solid waste such as fly ash and extending the coal industry chain is not only related to the sustainable development of China's coal industry, power industry and related industries, but also of great significance for protecting land resources, reducing and eliminating pollution and realizing a circular economy [9].

Domestic and foreign scholars have studied the extraction of alumina from fly ash since the 1950s. At present, there are many types of processes, which can be approximately divided into sintering, acid, alkali hydrothermal, etc. [10, 11]. Matjie et al. [12] used $\mathrm{NaOH}$ and $\mathrm{Na}_{2} \mathrm{CO}_{3}$ as roasting additives rather than limestone. The results showed that $\mathrm{NaOH}$ and $\mathrm{Na}_{2} \mathrm{CO}_{3}$ could effectively promote the decomposition of inert substances in fly ash. The extraction rate of $\mathrm{Al}_{2} \mathrm{O}_{3}$ reached $95 \%$ at $700{ }^{\circ} \mathrm{C}$. Ren [13] leached alumina from fly ash under pressure for $4 \mathrm{~h}$ with $50 \%$ sulfuric acid at $180{ }^{\circ} \mathrm{C}$. The extraction rate of alumina was as high as $82.4 \%$. Compared to the sintering and acid methods, the alkali hydrothermal method has the advantages of moderate energy saving, cleanliness and efficiency, and low equipment requirements; however, there are also shortcomings of excessive alkali circulation and the high causticity ratio of the extracted liquid. During recent years, the Institute of Process Engineering, Chinese Academy of Sciences, has proposed a two-step alkali hydrothermal process to extract aluminum. The extraction technology of aluminum from high-aluminum fly ash has been increased to $94.9 \%$, and the causticity ratio of the leaching solution has been reduced to 7.2 [14-17]. However, a large amount of circulating alkali remains in the alkali hydrothermal process and is the key factor restricting the industrialization of this aluminum extraction process, as well as its low efficiency. Based on the solubility of the sodalite in the hydrochloric acid, fly ash was converted into hydroxy sodalite, and then the aluminum component of the hydroxy sodalite was extracted into the solution in the form of an aluminum ion by hydrochloric acid, thus realizing the extraction of aluminum from the fly ash. As shown in the process flowchart in Fig. 1, this method not only improves the problem of high alkali consumption in the alkali-soluble extraction process of fly ash, but also realizes the simultaneous extraction or enrichment of other valuable metal ions, with a small amount of slag. It is a clean and efficient process for extracting aluminum from fly ash.

According to the experimental process shown in Fig. 1, hydroxy sodalite with a purity of $90.2 \%$ was successfully prepared under the optimal conditions of a water-alkali ratio of 1.5 , a water-cement ratio of 5 , a temperature of $220^{\circ} \mathrm{C}$, and a reaction time of $90 \mathrm{~min}$. It has been suggested that the hydrothermal synthesis of hydroxy sodalite from high-alumina fly ash might be the reaction of $\mathrm{SiO}_{3}{ }^{2-}$ ions [18] produced by a preferentially dissolved vitreous body and the direct row of $\mathrm{Na}^{+}$ions in solution on a mullite skeleton. The formation of new crystalline hydroxy sodalite is shown in Fig. 2.

\section{Experiment}

\subsection{Experimental raw materials}

Hydroxy sodalite was prepared from the fly ash of a thermal power plant in Inner Mongolia after alkali leaching. The chemical reagent, hydrochloric acid solution with a concentration of $36 \mathrm{wt} \%$, phenolphthalein reagent, amorphous silica, and alumina drugs of analytical pure grade and $\mathrm{NaCl}$ of edible salt grade were purchased from Beijing Co. Ltd. of the China Pharmaceutical Group.

\subsection{Experimental process}

Hydrochloric acid was used to dissolve and leach the solidphase system of the fly ash hydrothermal synthesis products. The Al element in the fly ash was mainly transformed and immobilized in the hydroxy sodalite, which is a small amount of silicate soluble in hydrochloric acid.

At the same time, valuable elements such as $\mathrm{Fe}$ and $\mathrm{Ti}$ in the solid-phase system can also be effectively leached and enriched through the leaching process of the hydrochloric acid. The experimental steps are as follows: first, weigh $2.5 \mathrm{~g}$ of solid reactant of each hydrothermal synthesis product and prepare a hydrochloric acid solution of different concentrations; second, mix a well-weighed and well-collocated solution into a $100-\mathrm{mL}$ conical bottle; third, heat the reaction 


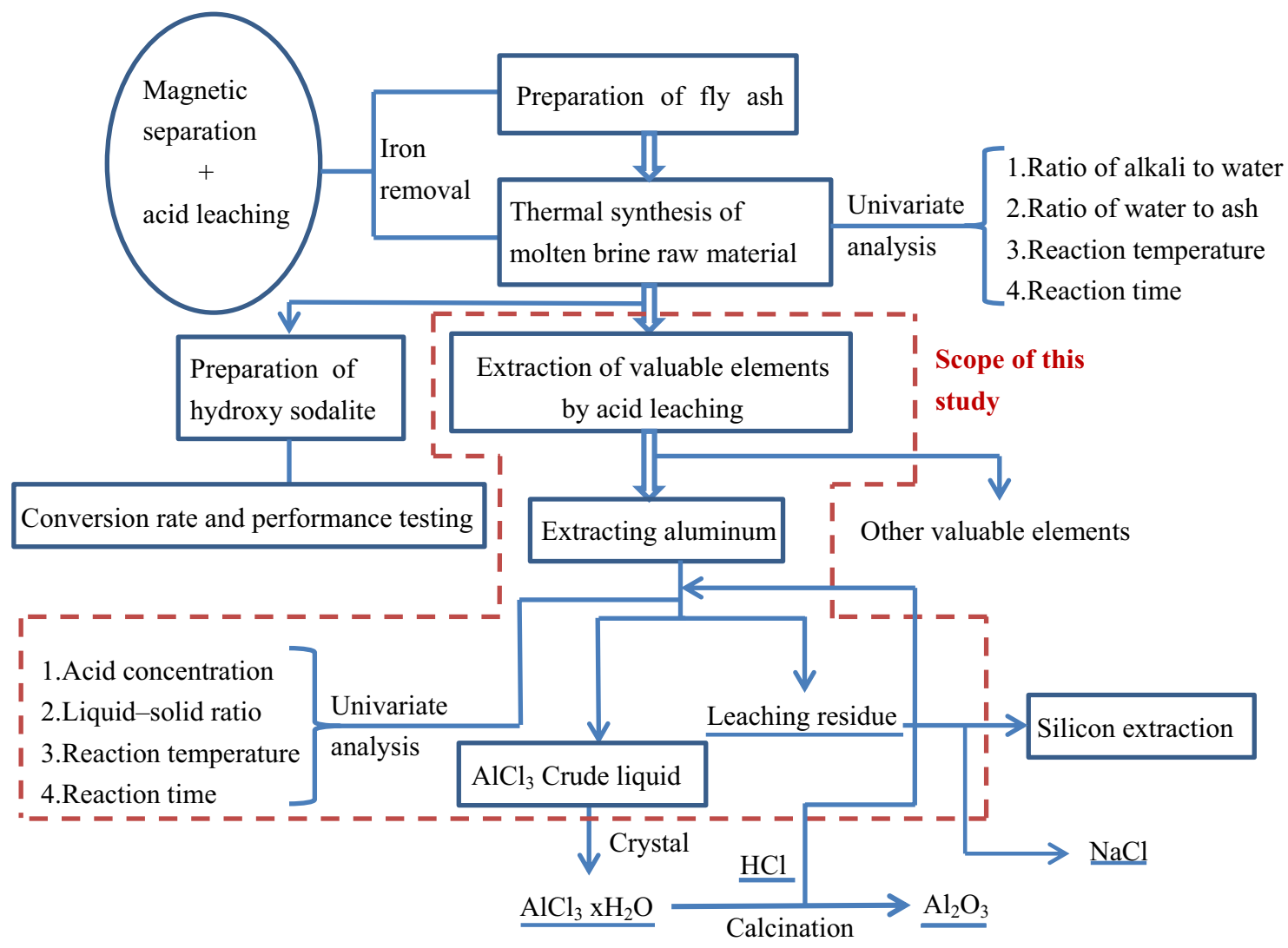

Fig. 1 Flowchart of comprehensive fly ash treatment

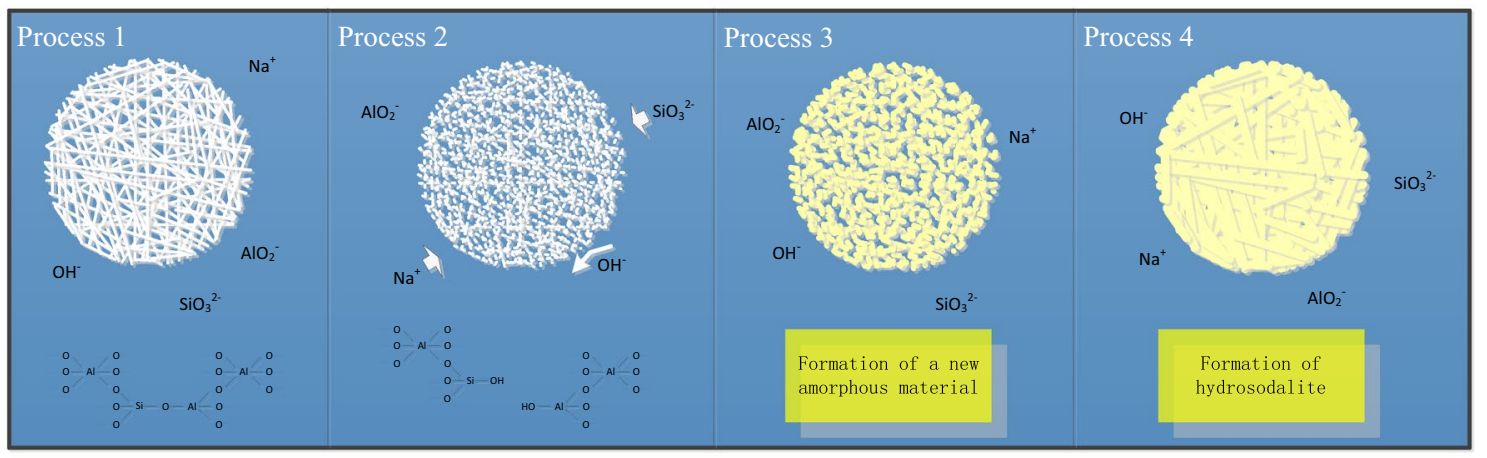

Fig. 2 Hydroxy sodalite conversion mechanism

system in a stirred thermostatic water bath for a certain time; fourth, remove the conical bottle and leak the product after the reaction. The bucket and quantitative filter paper are filtered to collect the filtrate. Fifth, dilute the filtrate to be detected. In this experiment, a single-factor method was used to study the effect of each factor. The different conditions and groups are shown in Table 1. The specific test process steps are shown in Fig. 3.

\section{Experimental results and analysis}

\subsection{Effect of different technological conditions on leaching of Al}

Following the first step of the alkali hydrothermal reaction in the molten salt system of Central Asia, most of the aluminum elements in the raw fly ash are transformed and fixed in the formed new phase, hydroxy sodalite, 
Table 1 Single-factor experimental conditions and groups for hydrochloric acid leaching

\begin{tabular}{|c|c|c|c|c|c|}
\hline \multirow{2}{*}{$\begin{array}{l}\text { Influential factor } \\
\text { Hydrochloric acid concentra- } \\
\text { tion (mol/L) }\end{array}$} & \multicolumn{5}{|c|}{ Factor level and group number } \\
\hline & $0.5(C-1)$ & $1.0(\mathrm{C}-2)$ & $1.5(C-3)$ & $2.0(C-4)$ & $2.5(\mathrm{C}-5)$ \\
\hline Liquid-solid ratio & $5(L-1)$ & $10(\mathrm{~L}-2)$ & $15(L-3)$ & $20(L-4)$ & $25(L-5)$ \\
\hline Leaching temperature $\left({ }^{\circ} \mathrm{C}\right)$ & $25(\mathrm{~T}-1)$ & $45(\mathrm{~T}-2)$ & $65(T-3)$ & $85(T-4)$ & $100(T-5)$ \\
\hline Leaching time (min) & $60(\mathrm{~S}-1)$ & $90(\mathrm{~S}-2)$ & $120(\mathrm{~S}-3)$ & $150(\mathrm{~S}-4)$ & $180(\mathrm{~S}-5)$ \\
\hline
\end{tabular}

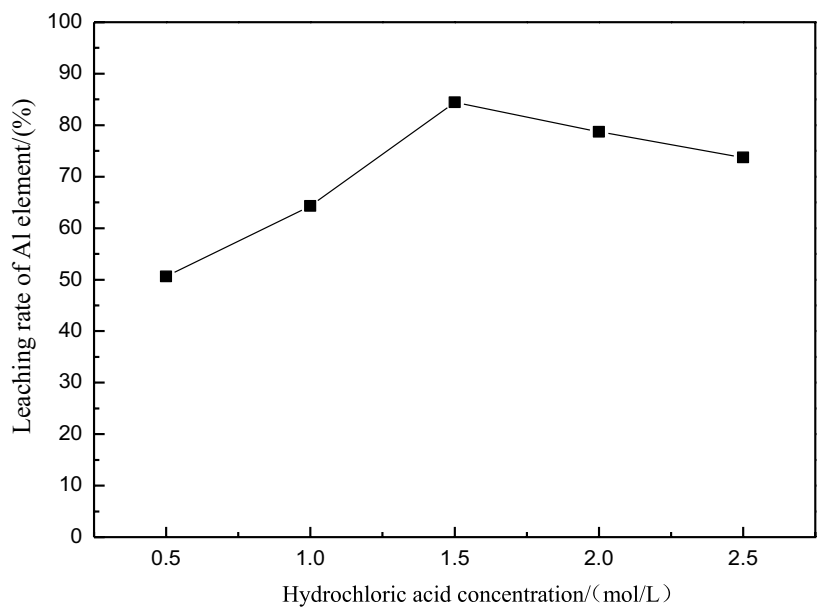

Fig. 4 Effect of hydrochloric acid concentration on aluminum dissolution rate in the hydroxy sodalite

leaching rate with the increase in the hydrochloric acid concentration at lower hydrochloric acid concentration. With the increase in the hydrochloric acid concentration, the formation of silica gel in solution gradually increases because of the transformation of the silicon elements in the solid phase; the formation of a large number of silica gels will hinder aluminum leaching, resulting in a slight decrease in the leaching rate. In the test results, C4 and C5 samples were gelatinized to different degrees after being placed in a static position, proving gel generation during the leaching process. The effect of the hydrochloric acid concentration on the leaching of aluminum in the hydroxy sodalite shows that the leaching rate will show a peak value during the leaching process. The concentration of hydrochloric acid used was low; thus $1.5 \mathrm{~mol} / \mathrm{L}$ can be determined as the optimal concentration of hydrochloric acid.

\subsubsection{Effect of liquid-solid volume-mass ratio on the aluminum leaching rate}

The volume-mass ratio of liquid to solid can reflect the influence of the reaction conditions and reaction limits on the leaching results. The volume-mass ratio of liquid to solid was determined on the basis of preliminary 


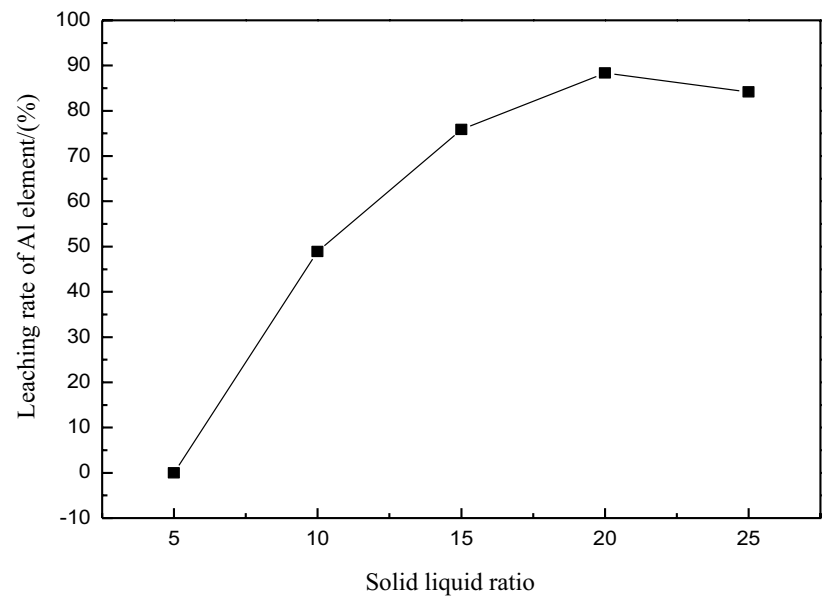

Fig. 5 Effect of the solid-liquid ratio on the aluminum dissolution rate in hydroxy sodalite

experiments. The liquid-solid ratio was $5,10,15,20$, and 25 , respectively. The numbers are $L 1, L 2, L 3, L 4$, and $L 5$. Other influencing factors maintained the optimal conditions obtained in the experimental study. The effect of the liquid-solid volume-mass ratio on the leaching of aluminum is shown in Fig. 5.

As shown in Fig. 5, when the volume-mass ratio of the liquid to solid is less than 20 , the leaching rate of the aluminum increases with an increase in the liquid-solid ratio, reaching a maximum value $(88.35 \%)$ when the liquid-solid ratio is 20 . This is because with the increase in the liquid-solid volume-mass ratio, hydroxy sodalite better disperse and more fully mix in the solution, and the kinetic conditions of the reaction system gradually improve. Moreover, because the initial concentration of hydrochloric acid is the same, the increase in the liquid-solid ratio is the increase in the hydrochloric acid content in the solution. When the reaction tends toward equilibrium, the concentration of the reactants and generated organisms in the corresponding system is higher than that in the liquid-solid system. Less than that, during the whole reaction process, the reduction in the reactant concentration is small, and the concentration of the hydrochloric acid in the system is always greater than that in the case of a small liquid-solid ratio. The reaction rate is accelerated and the reaction is more complete; thus, the leaching rate of aluminum increases with the increase in the liquid-solid ratio. When the liquid-solid mass ratio exceeds 20 , the leaching rate slightly decreases. This may be because of the presence of a certain amount of silicon in the hydroxy sodalite. With the increase in hydrochloric acid and the final concentration of the reaction system, silica gel, which affects the diffusion and reaction of the reactants, forms in the reaction system. It has been proven that $L 5$ of the filtrate sample with a higher liquid solid volume mass ratio gelatinizes after a few days of remaining stationary and converts to a jelly solid-liquid mixture. The aforementioned results and phenomena show that there is an optimal ratio of liquid to solid volume to leach aluminum from hydroxy sodalite with hydrochloric acid within a certain range; the optimal ratio of liquid to solid volume is 20 in this study. Of course, water demand, recovery conditions, and environmental factors can also be comprehensively considered, and more reasonable liquid-solid volume ratio conditions can be selected.

\subsubsection{Effect of leaching time on the aluminum leaching rate}

The reaction time of the leaching reaction reflects the reaction rate and can be used to measure the reaction progress under different reaction times. The single-factor analysis method is used to ensure that other influencing factors are constant. This experiment evaluates the preliminary experimental results and comprehensively analyzes the efficiency and energy consumption. Leaching conditions for $60,90,120,150$, and 180 min were determined. The leachate samples were numbered S1, S2, S3, S4, and S5, respectively. The effect of the leaching reaction time on the leaching of aluminum is shown in Fig. 6.

It can be seen that when the leaching time reaches $60 \mathrm{~min}$, the leaching rate of Al has reached a higher level, more than $80 \%$ as shown in Fig. 6 , and the leaching effect is ideal. When the time is less than $120 \mathrm{~min}$, the leaching rate of $\mathrm{Al}$ gradually increases with the prolongation of leaching time. After the more than $120 \mathrm{~min}$, the leaching rate no longer obviously increases with the prolongation of time. A plateau of the leaching rate appears, and the leaching rate tends to be stable and the reaction tends to be balanced. From the overall trend shown in Fig. 8, the

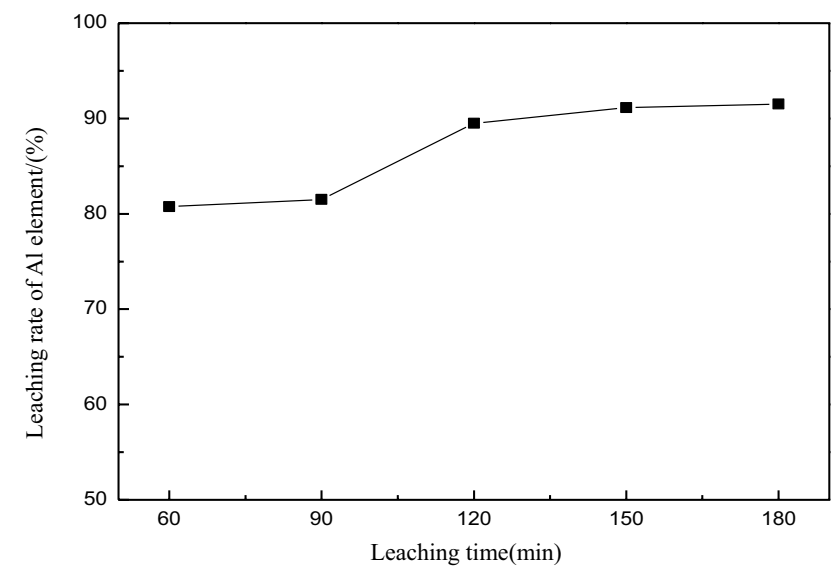

Fig. 6 Effect of reaction leaching time on aluminum dissolution rate 
leaching time has little effect on the leaching rate of $\mathrm{Al}$ in hydroxy sodalite leached by hydrochloric acid. This may be because the dissolution reaction of hydrochloric acid to hydroxy sodalite readily occurs, and under stirring conditions, the kinetic conditions are good. The powder structure of hydroxy sodalite also provides a larger reaction contact area; thus, the reaction rate is faster. However, during the later stage of the reaction, the contact area of the reaction significantly decreases because of the reduction in the volume of hydroxy sodalite, and the concentration of the hydrochloric acid in the mother liquor decreases with the extension of the reaction time and the progress of the reaction. The increase in the leaching rate gradually slows. Under this experimental condition, the leaching rate basically reached its highest value after $120 \mathrm{~min}$, and the increase in the reaction time had no effect on the increase in the leaching rate. Therefore, the selection of leaching time should be within $120 \mathrm{~min}$. At the same time, one can choose the best technological conditions by considering various factors.

\subsubsection{Effect of leaching temperature on the aluminum leaching rate}

Leaching temperature is an important factor affecting the reaction rate and controlling the equilibrium of the reaction. The dissolution reaction is essentially an endothermic reaction type. Increasing the leaching reaction temperature can not only greatly accelerate the dissolution rate, but also promote the reaction to proceed forward and make it more complete, thus improving the leaching rate. During this experiment, the single-factor analysis method was used to ensure that the level of non-investigative factors was constant. The influence of leaching temperature on leaching rate was investigated using an open system at atmospheric pressure, with water bath heating and a temperature from room temperature to boiling. Temperature points were as follows: $25,45,65,85$, and $100^{\circ} \mathrm{C}$ test levels, unit temperature. The leaching liquors of samples were numbered $\mathrm{T} 1, \mathrm{~T} 2, \mathrm{~T} 3, \mathrm{~T} 4$, and $\mathrm{T} 5$, respectively. The experimental results of the effect of the leaching temperature on the leaching of aluminum are shown in Fig. 7.

As shown in Fig. 7, the leaching rate of $\mathrm{Al}$ increases with the increase in the reaction temperature, and the rising trend slows. When the leaching temperature exceeds $85^{\circ} \mathrm{C}$, the leaching rate does not increase. It can be seen that the increase in the leaching temperature not only affects the reaction rate, but also enlarges the reaction limit of the leaching reaction making it more complete. From the point of view of leaching rate, when other setting conditions are unchanged, the optimal

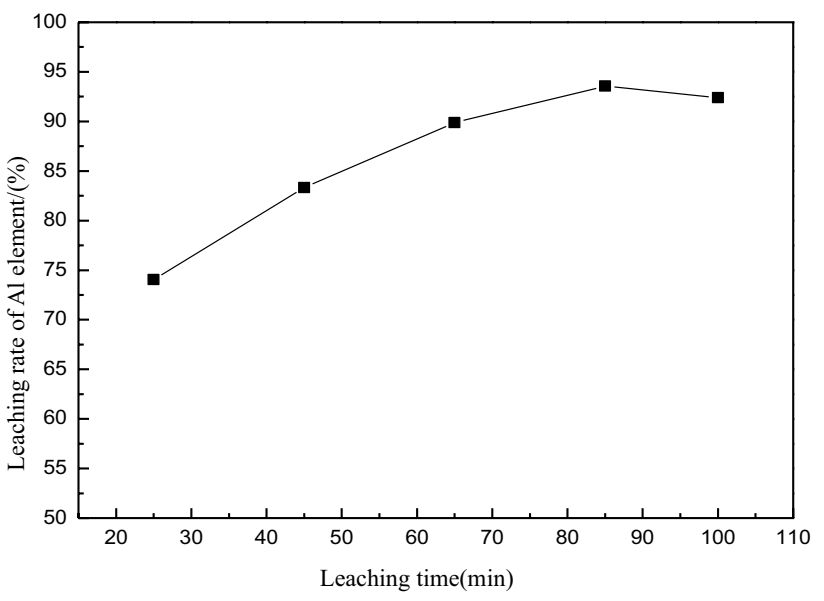

Fig. 7 Effect of reaction leaching temperature on the leaching rate of $\mathrm{Al}$

leaching temperature is $85^{\circ} \mathrm{C}$, at which the highest leaching rate is obtained.

Hydroxy sodalite, a product of hydrothermal synthesis of fly ash, can be leached out by hydrochloric acid in the form of a silicate. The leaching rate can reach more than $90 \%$, and the $\mathrm{Al}$ in the leaching solution exists in the form of $\mathrm{Al}^{3+}$. The leaching time has little effect on the concentration of the hydrochloric acid leaching solution.

\subsection{Raw material characteristics}

The fly ash used in the test material is high-alumina fly ash from a thermal power plant in Inner Mongolia. Through $x$-ray fluorescence (XRF) analysis of its composition, it was found that the content of silica and aluminum was as high as high as $90 \%$, and the molar ratio was approximately $1 / 1$. It was an excellent synthetic material for modified zeolite. XRD results show that the fly ash mainly consists of crystalline mullite, quartz, corundum, and silica-alumina oxides as amorphous glasses containing a small amount of impure metals. Table 2 and Fig. 8 present the composition and phase composition of fly ash used during the experiment, respectively.

\subsection{Phase and microscopic morphology analysis of leaching residue}

\subsubsection{Phase analysis of leaching residue filter cake}

To study the hydrothermal reaction process of fly ash and the leaching mechanism of the valuable elements in the reaction between the synthetic products and hydrochloric 
Table 2 Elemental composition and content of high-aluminum fly ash

\begin{tabular}{lllllll}
\hline Elements & $\mathrm{SiO}_{2}$ & $\mathrm{Al}_{2} \mathrm{O}_{3}$ & $\mathrm{CaO}$ & $\mathrm{Fe}_{2} \mathrm{O}_{3}$ & $\mathrm{TiO}_{2}$ & Else \\
\hline Contents $\%$ & 47.72 & 41.63 & 3.57 & 2.89 & 1.82 & 2.37 \\
\hline
\end{tabular}

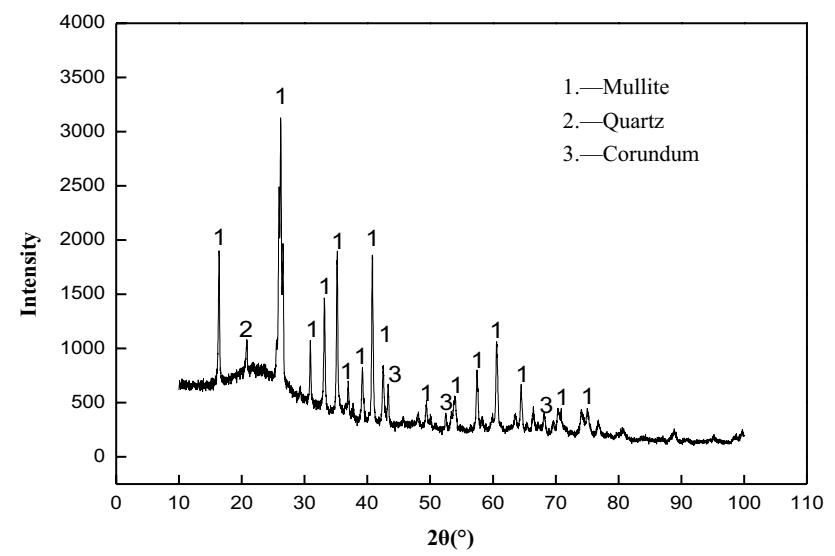

Fig. 8 XRD diffraction spectrum of fly ash

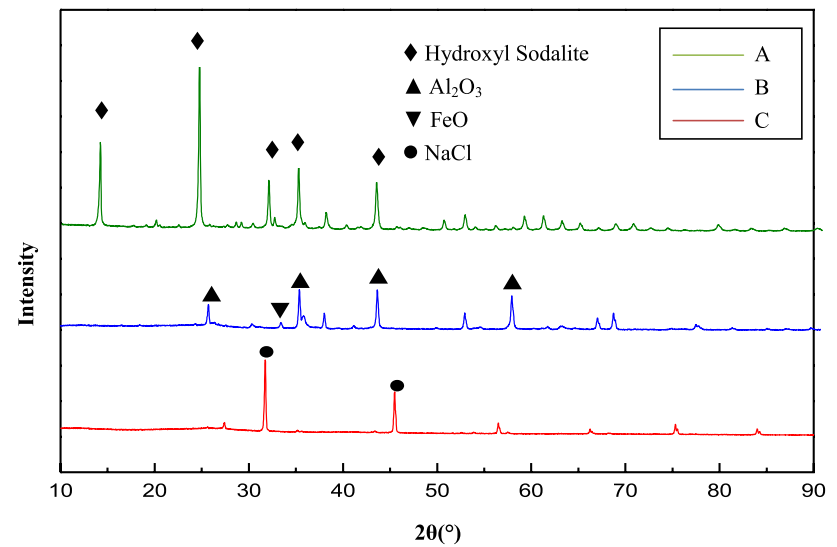

Fig. 9 Sample A (hydroxy sodalite), B (inferior hydrochloric acid leaching residue) and $C$ (superior hydrochloric acid leaching residue) XRD contrast atlas

acid, the phase of one hydroxy sodalite product sample and two representative leaching residue filter cake samples was tested under the following conditions: sample $A$ (hydroxy sodalite sample), sample $B$ (solid volume ratio of hydrochloric acid to synthetic sample 5), and sample $C$ (hydrochloric acid and synthetic sample liquid-solid volume-mass ratio 25$)$. The XRD contrast map is shown in Fig. 9.

From Fig. 9, it can be seen that the phase of the solidphase system of the fly ash hydrothermal synthesis product essentially changed after leaching with hydrochloric acid. Moreover, it was found that the quality of the hydrochloric acid leaching residue greatly decreased and was only approximately $10 \%$ of the solid phase before leaching. Sample $A$ is a product of fly ash hydrothermal synthesis. The solid phase of sample $A$ is mainly hydroxy sodalite with a mass content of greater than $90 \%$. Sample B is mainly in the form of alumina and silica-alumina oxides, indicating that the crystalline structure of the hydroxy sodalite was destroyed and the product formed a stable phase related to the silica-alumina oxides. The phase of sample $\mathrm{C}$ mainly exists in the form of $\mathrm{NaCl}$, indicating that the silica-aluminum substance in the solid-phase system was completely dissolved by the hydrochloric acid. The Al exists in the leaching solution in the form of $\mathrm{Al}^{3+}$, while it dissolves in the hydrochloric acid solution in the form of small or large molecules; the other part remains in the solid phase as the main part of the hydrochloric acid leaching residue in the form of silica gel.

\subsubsection{Microscopic morphological analysis of the leaching residue filter cake}

To determine the phase of the hydrochloric acid leaching residue of the fly ash synthesis product, phase changes before and after leaching were studied. The microstructures of the hydroxy sodalite and two types of leaching residues from the fly ash hydrothermal synthesis were characterized and compared: sample A (hydroxysodalite), sample $B$ (hydrochloric acid and synthetic sample liquid-solid mass ratio 5), and sample $C$ (hydrochloric acid and synthetic sample liquid-solid mass ratio 25 ). The scanning electron microscopic pattern is shown in Fig. 10.

From Fig. 10, it can be seen that the morphology and structure of the hydroxy sodalite, a product of the fly ash hydrothermal synthesis, significantly changed after acid leaching. Comparing the three groups of photographs, one can see that there are significant differences in the morphology and stacking mode of the three groups. By observing the micromorphology of sample $A$, one can see that the particles are dispersed in a spheroid-like structure, and there are some voids and spaces between the particles. Meanwhile, the microunit structure of sample $B$ shows a relatively close stacking of collapsed and damaged structures, indicating that after leaching with hydrochloric acid, the particles dispersed. The spherical structure of hydroxy sodalite was completely destroyed. It was also confirmed that the hydroxy sodalite was dissolved 

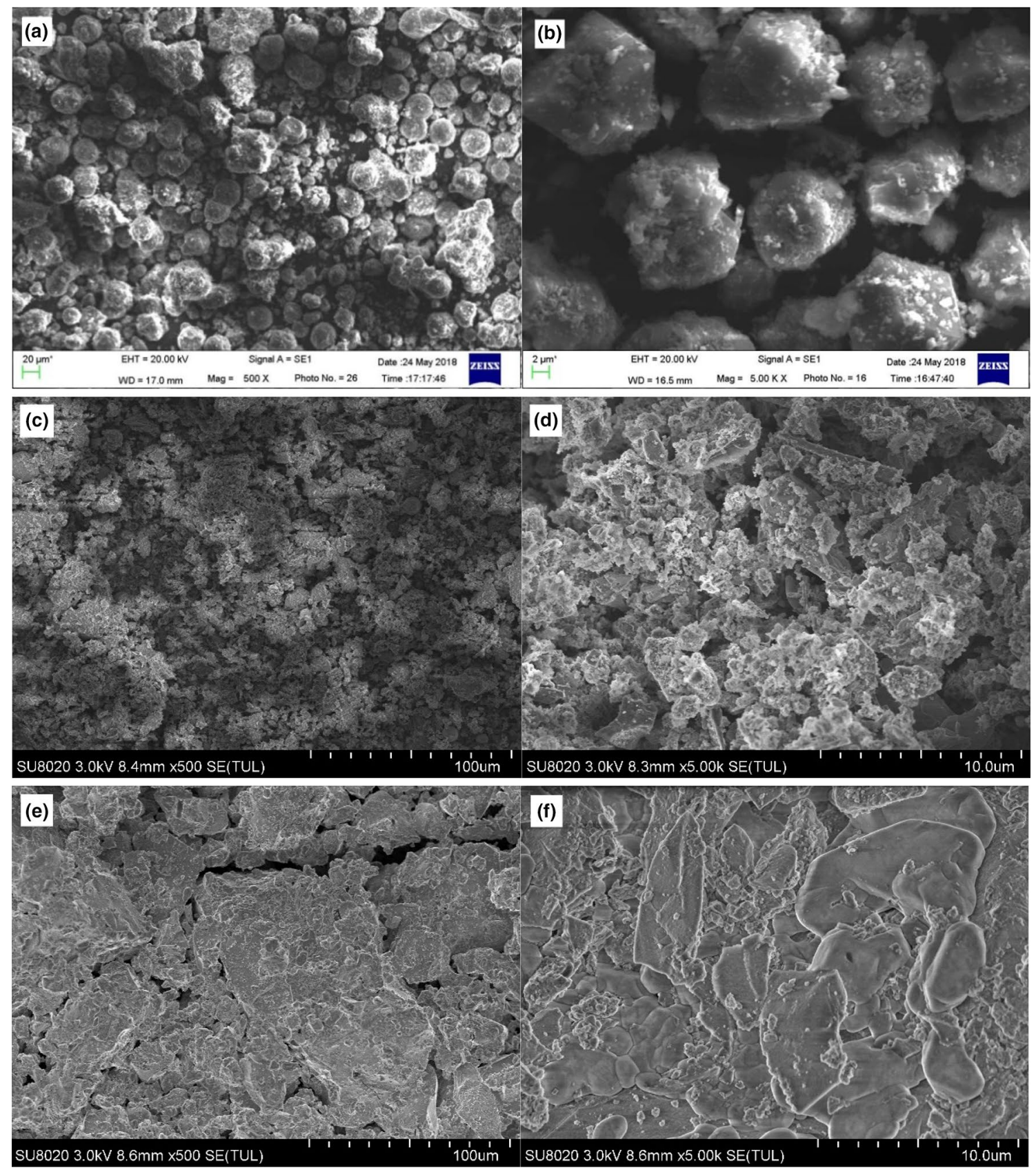

Fig. 10 Scanning electron microscope of sample A (a, b), Sample B (c, d), Sample C (e, f) at 500 and 5000 magnification

by hydrochloric acid to form a new silica-alumina oxide structure. In Fig. 10e, f, smaller structural units and further compact accumulation structures are presented, similar to sediment accumulation, indicating that the dissolution reaction is more thorough, with only a few insolubles and newly formed silica gel. In combination, the micromorphology and structure shown in Fig. 10e, fare formed.

\section{Summary}

The leaching rate of aluminum in the solid-phase system of hydrothermal synthetic products can be calculated by the leaching effect of hydrochloric acid. Through analysis, detection, and calculation, several conclusions were obtained as follows: 
1. The leaching rate of aluminum can reach more than $90 \%$. The main factors affecting the leaching rate are the hydrochloric acid concentration, liquid-solid volume ratio, reaction temperature, and reaction concentration. The leaching rate peaks with a change in the hydrochloric acid concentration and liquid-solid volume ratio. Within the scope of this study, the optimal leaching concentration is $1.5 \mathrm{~mol} / \mathrm{L}$ and the optimal liquid-solid volume ratio is 20 . With an increase in temperature and time, the concentration of hydrochloric acid and the volume-mass ratio of liquid to solid have a greater impact on the leaching rate.

2. In the solid-phase system, the silica-aluminum substance is basically completely dissolved by the hydrochloric acid. The Al exists in the leaching solution in the form of $\mathrm{Al}^{3+}$, while the $\mathrm{Si}$ is partly dissolved in the hydrochloric acid solution in the form of small or large molecules, while the other part is retained in the solid phase as silica gel and becomes the main part of the hydrochloric acid leaching residue. Using this method, other valuable elements such as titanium can be simultaneously enriched.

3. Carbon in hydrochloric acid leaching residue is enriched, and the carbon content reaches $30 \%$, achieving a recovery value. In addition, the $\mathrm{NaCl}$ content in the unwashed leaching residue is more than 35\%; thus, $\mathrm{NaCl}$ in the hydrochloric acid leaching residue can be recovered.

Acknowledgments Authors are thankful to Datang Corporation and Shandong Iron and Steel Group for providing fly ash and steel slag.

Author contributions $\mathrm{YZ}$ has been leading the research project, obtaining funding acquisition and conceptualization as well as writing review and editing. FL has designed, conducted the experiments, and written this work. WC and ZL have been writing review and editing.

Funding This research was funded by the National Natural Science Foundation of China (Grant No. 51474028), Ministry of Science and Technology of China (Grant No. 2017YFC0210301) and People-benefit project of Ningbo Science and Technology (Grant No. 2015C50058).

\section{Compliance with ethical standards}

Conflict of interest The authors declare no conflict of interest.

\section{References}

1. Ahmaruzzaman $M$ (2010) A review on the utilization of fly ash. Prog Energy Comb Sci 36(3):327-363

2. Cao DZ, Selic E, Herbell J (2008) Utilization of fly ash from coalfired power plants in China. J Zhejiang Univ Sci A 9(5):681-687

3. Cheng XF (2016) Present situation of exploration and development of bauxite resources in china and suggestions for sustainable development. Resour Ind 03:16-22

4. Du ZC, Li HQ, Bao WJ et al (2011) Reaction mechanism of alkali dissolution and desilication of high aluminum fly ash. J Process Eng 03:442-447

5. Hu XQ, Peng TJ, Sun HJ et al (2016) Formation mechanism of hydroxyl sodalite. J Chin Ceram Soc 44(8):1200-1206

6. Jiang JC, Zhao YC (2008) Current research situation of al extraction from fly ash. Nonferrous Met Eng Res 2:40-43

7. Halina M, Ramesha S, Yarmob MA, Kamarudin RA (2007) Nonhydrothermal synthesis of mesoporous materials using sodium silicate from coal fly ash. Mater Chem Phys 101:344-351

8. Guo Y, Li Y, Cheng F et al (2013) Role of additives in improved thermal activation of coal fly ash for alumina extraction. Fuel Process Technol 110:114-121

9. Lei R, Fu DS, Li GF et al (2013) Research progress on comprehensive utilization of fly ash. Clean Coal Technol 03:106-109

10. Li HQ (2014) A method of preparing aluminum hydroxide from high aluminum fly ash: China, CN201210364147.X. 2014-03-26

11. Li HQ, Xu DH, Wang CH et al (2016) Study on two-step alkali hydrothermal leaching of alumina from high aluminum fly ash. Light Met 12:5-10

12. Matjie RH, Bunt JR, Heerden JHP (2005) Extraction of alumina from coal fly ash generated from a selected low rank bituminous South African coal. Min Eng 18:299-310

13. Ren Q (2012) Characteristic analysis and resource utilization evaluation of fly ash. Southwest Jiaotong University

14. Sun L, Li HB (2013) Significance of development and utilization of high aluminum fly ash and comparative analysis of technologies. North Environ 29(5):47-49

15. Sun ZH, Bao WJ, Li HQ et al (2013) Phase transition in alkali solution and extraction of aluminum from high aluminum fly ash by pre-desilication. J Process Eng 03:403-408

16. Wang ZT (2013) The industrialization era of high-alumina fly ash comprehensive utilization is coming. Light Met 4:78

17. Wu CY, Yu HF, Zhang HF (2012) Extraction of aluminum by pressure acid-leaching method from coal fly ash. Trans Nonferrous Met Soc China 22(9):2282-2288

18. YaO ZT, Ji XS, Sarker PK et al (2015) A comprehensive review on the applications of coal fly ash. Earth Sci Rev 141:105-121

Publisher's Note Springer Nature remains neutral with regard to jurisdictional claims in published maps and institutional affiliations. 